\title{
SCOPE OF AESTHETICS IN THE GAME MODEL OF ARTWORKS, WHICH CONTAINED FUNCTION OF AUGMENTED REALITY
}

\author{
Svetoslav Kosev, kosevsa@ts.uni-vt.bg
}

"Cyril and St. Methodius" University of Veliko Tarnovo, Bulgaria

Abstract: As I have repeatedly emphasized, processes in the field of technology and their application for the purposes of the visual arts have always played a major role in the development of my creative vision. An essential role in this direction has my acquaintance with Atanas Markov, with whom we complement each other in many respects and this has a beneficial effect on our teamwork. We have already shared in a previous edition of the conference "Cultural and Historical Heritage" about the work on the projects "Interactive Generative Formations", "Virtual Arena" and "Interaction with a technological organism". We are currently developing an extension of the last of the listed installations. This upgrade consists of the creation of a series of two-dimensional works in which an element of augmented reality must be included. This is essentially not something that has not already been done, but it is a very good element that would contribute the communication with the "Technological organism". The relation is also implemented at the level of interaction, and we rely on the game moment again. Through this act, we involve the observer, as an active participant in the artwork.

Keywords: Augmented Reality, Interactive Art, Game, Game Model, Artwork

\section{ОБХВАТ НА ЕСТЕТИКАТА В ИГРОВИЯ MOАЕА НА ХУАОЖЕСТВЕНИ ПРОИЗВЕАЕНИЯ С ФУНКЦИЯ НА АОБАВЕНА РЕААНОСТ}

Светослав Косев, kosevsa@ts.uni-vt.bg

Великотьрновски университет „Св. св. Кирил и Методий“, България

Резюме: Както неведнъж съм полчертавал, процесите в областта на технологиите и приложението им за целите на визуалните изкуства, винаги са играли основна роля за развитието на творческите ми възгледи. Съществена роля в тази насока, играе познанството ми с Атанас Марков, с когото се Аопьлваме в много отношения и това оказва ползотворно влияние на екипната ни 
работа. Вече сполелихме в предишно издание на конференцията „КУАтурно историческо наслеАство“, за работата по проектите "Интерактивно генеративни формации“, "Виртуална арена" и „Взаимодействие С технологичен организъм“. В момента разработваме разширение на посленната от изброените инсталации. Това налграждане се състои в създаването на серия Авуизмерни произведения в които трябва $\Delta а$ бъ $\Delta е$ вк^ючен елемент на добавена реалност. Това по същество не е нещо, което вече не е правено, но е много удачен елемент, който би допринесъл за илеята по отношение на комуникацията с "технологичния организьм". Врьзката се осъществява и на ниво интеракция, в която отново залагаме на игровия момент, чрез който въвличаме наблюдателя, като активен участник в произведението.

КАючови Ауми: Аобавена реалНост, интерактивно изкуство, игра, игрови моАеА, художествено произвеАение.

През месец май 2019 голина, беше открита изложба, която съпьтстваше фринален етап от пьрвата част на проекта „Превьп^ьщенията на книгата". Това е проект, представен от името на група Co-interaction, която беше основана от мен и Атанас Марков. Групата има за цел $а$ с съзава и подкрепя проекти, свързани с интерактивността, което по ссказва и наименованието иे. СьзАаването й беше провокирано от фокта, че с Наско бяхме разработили Ава такива проекта и работехме по трети. Тогава колегата Биляна Цанова спомена, че може би е време да създалем група, тъй като вече имаме Аостатъчно общи проекти и би било добре $\Delta а$ се представяме с обобщаваща интересите ни кооперация. СлеА като обмисляхме известно време варианти, в крайна сметка се спряхме на наименованието Соinteraction. Проектите, които бяхме съзАали с Атанас са „Интерактивно генеративни формации“ и „Виртуална арена“, а проектьт по който работихме тогава е „Взаимодействие с технологичен организъм“. За тях вече стана въпрос в предхолни изАания на конфреренцията "Културноисторическо наслелство: опазване, представяне, Аигитализация", а настоящия материал е във връзка с прольлжението на послеАния ат тях. За ла прольлжа изложението си обаче, ще се спра на проекта "Превьп^ъщенията на книгата", който също е част от инициативите на група Co-interaction. Интересното при този проект е, че беше разработен съвместно от мен и Симеон Желев. За него също говорихме с него в предходното издание на конореренцията. 
Тук обаче ще обърна внимание на елин от аспектите на проекта, който има връзка със сегашната тема, а именно добавената реалност.

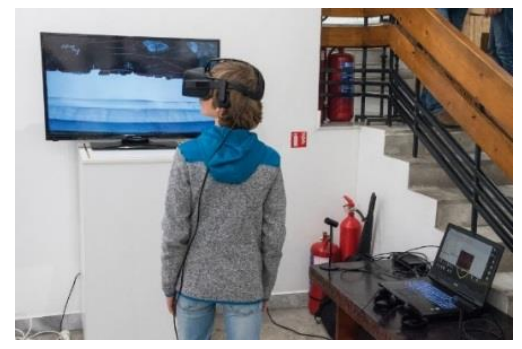

Фиг. 1. Наблюдение на персонаж чрез VR технология.

Целта на проекта „Превьпльщенията на книгата“, е ла сьчетава различни по същността си изразни среАства в изобразителното изкуство, като еАно от тях е виртуалната реалност VR (Фиг.1). Освен съзАалените с помощта на софртуерни продукти за триизмерна графрика сцени, които впослеАствие послужиха за отпечатване на графрични творби, а те на свой реА превьрнати в рьчно изработени книги, беше съзАалена и виртуална сцена.

В нея беше интегриран Аракон в стил стиймпьнк, който ползвах за и^юстрирането на "Песен 34" от произведението на Аанте Алигиери "Божествена комедия“, част пьрва „АА“ (Фиг.2). Целта беше $\Delta а$ се използва 3D молела, за съзАаване на произведение на изкуството с Аруги

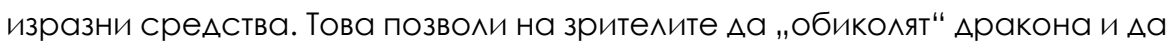
го разгледат от всички страни. Специфриката при виртуалната реалност е в технологията, която изисква специално оборудване и по-конкретно очилата, които проектират инАивиАуална визуализация за вСяко отАеАно око, което може $А$ с се види на първата илюстрация. Обстановката в която попаАа човек, е изцяло синтетично съзАадена, което означава, че зрителя е напьлно потопен в „Света“ и обкрьжението, проектирани от твореца.

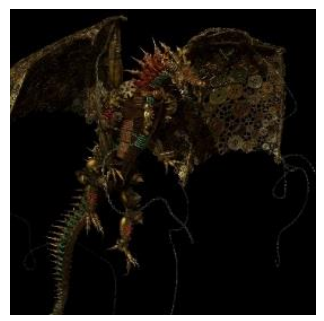

Фиг. 2. И^юстрация към „Божествена комеАия“ - Аанте А^игиери. 
Аа се върнем на проекта „Взаимодействие с технологичен организъм“. В началото на юни 2021 предстои представяне на инсталацията в галерия "Аоза" - Софрия. Тъй като заради COVID-19 пандемичната обстановка, направихме елна принудителна Аьлга пауза, свързана с осъществяването на културни събития в общественото пространство, решихме да полновим работата по проекта и $и$ го представим в по широка среда. Времето ще покаже дали това ще се осъществи! За да налградим вече показаното във Велико Търново на 15

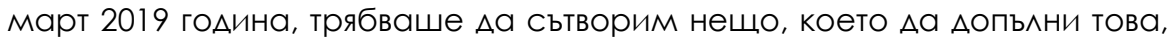
което вече сме създали. Разсъждавайки какво да представлява това Аопьлнение, Атанас преАложи Аа бъдат съзАалени няколко творби, които Аа вкАЮчват набиращата все по-голяма популярност Аобавена или обогатена реалност $\triangle P$ (Augmented reality).

Вземайки предвил определението за Аобавена реалност на Рона^А Азума, което се ползва често в научната митература (Azuma, 1997), то може $а$ а се каже, че тя е разновидност на виртуалната реалност. Основната разлика при двете е, че както казах по-рано във виртуалната реалност, реципиентьт е изцяло потопен в среАата сьзАалена от твореца, Аокато при Аобавената реалност имаме смесване на реалната със синтетично съзАалената среАа. СлеАователно $\triangle Р$ Аопьлва реалността, вместо Аа я замества напьлно.

СпореА някои изследователи, добавената реалност изисква използването на специални очи^а-дисплеи (HMD) по начин, подобен на виртуалната реалност. Спорел Азума обаче, „за $а$ а се избегне ограничаването на Аобавената реалност $А$ специфични технологии, тя маже да бъле определена като система, която има сленните три характеристики:

1. Комбинира реално и виртуално;

2. Интерактивна е в реално време;

3. Функционира в триизмерното пространство."

Според него, чрез тази дефриниция се Аава възможност за използването и на Аруги технологии, освен специално съзАалените очила-дисплеи, като същевременно основните компоненти на Аобавената реалност се запазват. 
Според това определение, продукти на фриммовата индустрия или колажи от изображения не биха могли $А$ влязат в тази категория.Чрез разширяването на обсега от технологии, които се използват за Аобавена реалност, значително се увеличава и нейната Аостьпност. В момента има редица приложения, които могат Аа бъАат инсталирани на смарторон и $А$ a използват АОбавената реалност, като това най-често става поА фрормата на някакьв виА забавление.През 2016 г. например, стартира играта Pokémon GO, която бързо набра популярност. Тази игра използва местоположението на приносителя на смарторона в съчетание с обогатена реалност. Играта позволява на играчите $А$ „АОвуват“, $А$ водят битки и Аа обучават виртуални същества, наречен покемони (Pokémon).Те се появяват на цисплея на мобилното устройство, внеАрени в обстановката на реалния свят. Разпрьснати са в реални градове и населени места по целия свят. Това е възможно благодарение на съвместното използване на GPS и камерата на мобилното устройство. ВпослеАствие обаче тази игра беше обявена за опасна, тий като играещите се абстрахират от реалноста, сьсреАоточени най-вече в Аисплея на мобилното устройство. По този начин съзАават преАпоставки най-вече за

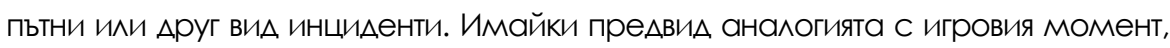
чрез който се опитваме $а$ в въвлечем зрителя, за $л а$ се превърне в част от произведението, ние се опитваме Аа събудим неговото мюбопитство, като го предизвикаме $А$ взаимодейства с инсталацията. По отношение на преАизвикателството може $\Delta а$ се каже, че освен инАивиАуалното му въздействие, то е и Аинамично. Този когото се опитваме $А$ въвлечем в Аействието, може Аа намери еАна цел за преАизвикателна в началото, но С^еА като бъ $\Delta е$ изпьлнена, тя ще престане $\Delta а$ бъле такава. Така процесьт трябва $\Delta а$

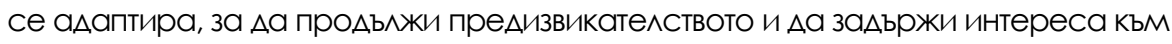
игровия елемент (Fullerton, 2014).

Има ли начин да се разгледа предизвикателство, което не е Аесринирано чрез инАивиАуално преживяване? Съществува Аи общовалиАно опреАеление, което може $А$ н ни $А$ ае цялостна иАея, която $\Delta \mathrm{a}$ имаме предвиА при проектирането? Когато се заемем със съзАалете основното преАизвикателство, Можем Аа започнем, като помислим какво преАизвиква раАост у хората и кои виАОве Аейности ги правят щастАиви. Оказва се, че отговорьт на този вьпрос е пряко свързан с концепцията на 
преАизвикателството и неговото ниво на преАизвикателност, приАобито чрез преживяването. Психологт Михай Чиксентмихай (Mihaly Csikszentmihalyi) (Csikszentmihalyi, 2014) си поставя за цел Аа илентифицира елементите на удоволствие, като изучава сходствата на изживяването при много различни залачи и типове хора. Това, което открива е изненалващо и то гласи „Независимо от възрастта, социалната к^аса и^и пола, хората описват Аейностите, които са им Аоставили удоволствие по сходен начин“. Самите Аейности обхващат различни сорери на забавление, включително музикални концерти, скално катерене, рисуване, игри, но думите и понятията, които хората изпо^зват за Аа опишат уАово^ствието преАизвикано от тях, се оказват подобни. Във всички тези задачи хората споменават определени елементи, които правят Аейностите приятни за тях:

- Пьрво, изживяването на насладата обикновено възниква, когато се сбльскаме със залачи, които имаме шанс да разрешим.

- Второ, трябва да можем да се концентрираме вьрху това, което правим.

- Трето и четвьрто, концентрацията обикновено е възможна, тъй като поставената залача има ясни цели и същевременно осигурява незабавна обратна връзка.

- Пето, човек се отлава на участието си в играта без усилие, което премахва от съзнанието тревогите и проблемите на ежеАневието.

- Шесто, приятните изживявания позволяват на хората да упражняват чувство на контрол върху своите Аействия.

- Селмо, чувството за самосъхранение изчезва, но паралоксалното е, че това усещане може $а$ а се засили слеА приключване на изживяването.

- Накрая усещането за продьлжителността на времето се променя. Часовете преминават в минути, а минути могат $а$ а се проточат така, че $\Delta$ а се усещат като часове.

Комбинацията от всички тези елементи предизвиква усещане за Аьлбоко уАоволствие, което е толкова възнагражАаващо, че хората имат усещането, че изразходват много енергия, което означава, че прекараното време си струва зарали това усещане. Ако нивото на предизвикателство остава поАХоАящо за нивото на способност и ако това преАИзвикателство се покачи с нивото на способноста, човекьт ще остане в центьра на центьра и ще изпита състояние, което Чиксентмихай нарича „поток“. 
В процеса на далена Аейност човек балансира межАу предизвикателство и способност, неудовлетвореност и скука, за Аа съзАале опит за постижения и щастие. В игровата индустрия съществува територия, която се намира в перифрерията на това, което считаме за игра (G. GeorgievaTsaneva, 2019). Те се развиват в областите на образованието (N. Sabev at all 2020), политиката, зАравеопазването (G. Georgieva-Tsaneva, 2018), изкуството, архитектурата и $А$ р. В процесът на създаване на интерактивните проекти с Атанас, ние сме вземали пол внимание някои от разгледаните елементи, като естествено се има преАвиА, че крайната ни цел е била произведение на изкуството. Естествено за нейното постигане, подобен виА изслеАвания са само от полза. Ситуацията с налгражАането на досега съзАалените проекти, чрез използването на Аобавена реалност има сходна цел. Що се

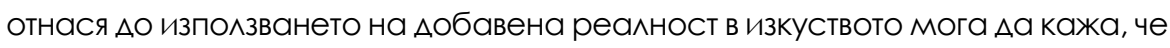
това е еАна територия, която тепьрва прохожАа, но бързо набира скорост.

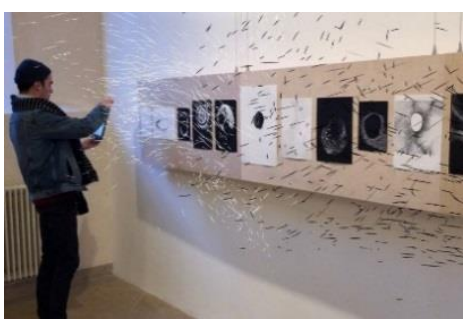

Фиг. 3. Изможба на арт група Adrien $M$ \& Claire B.

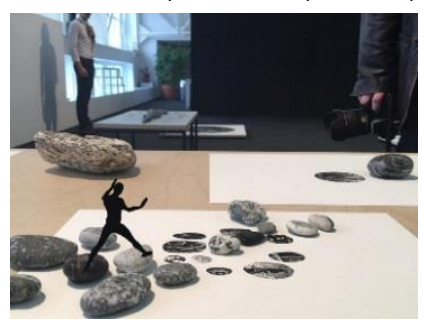

Фиг. 4. Изложба на арт група Adrien M \&. Claire B. ${ }^{1}$ - Аобавена реалност

Наскоро в социалните мрежи попалнах на елна впечатяяваща изложба на орренската арт група Adrien M \& Claire В. Впоследствие се оказа, че изложбата се е състояла през 2017 г., но както и ма е. Тази изложба е сьставена от серия графични изображения, които са поставени както по стените на изложбеното пространство, така и на пола. Посетителите разглежАат произведенията чрез таблети или мобилни устройства, като вижАат анимации или АОПьАнителни изображения, които се наслагват върху реалните творби и ги обогатяват (Фиг.3). Върху поставените хоризонтално графрики например, преАставляващи композиция от графично пресьздалени камьчета,

${ }^{1}$ [https://www.am-cb.net/en/projets/mirages-miracles ] Посл.посетен: 10-05-2021 
Изникват триизмерни такива, а върху тях подскача мъничък силует (Фиг.4). Подобна е и илеята за допьлването и обогатяването на проектите "Интерактивно генеративни формации“ и „Взаимодействие с технологичен организъм" чрез Аобавена реалност, като разбира се целта е $\Delta$ व се съзАале инАивиАуален естетически ефрект. В заключение мога $\Delta а$ кажа, че съчетанието на интердисциплинарни елементи, с цел създаването на арт продукт, разширява своя обхват във все по-широк Аиапазон, а резултатите са все по-неочаквани и интригуващи. Отражението от развитието на технологиите върху тези резултати е значително, а желанието на творците $\Delta а$ експериментират с нововъведенията, спомага процеса по взаимно преплитане на изкуствата и техническите постижения. ИнтерАисциплинарността в новопоявилите се изразни средства осигурява по-голям шанс за постигане на индивидуален резултат в творческите проекти, въпреки че както винаги съществува и известен риск, добра илея $\Delta а$ не бъде забелязана или добре разбрана при нейната поява.

\section{LITERATURE ( $\triangle$ UTEPATYPA)}

Azuma, R., (1997). A Survey of Augmented Reality. Teleoperators and Virtual Environments. 6 (4), pp. 355-385.

Fullerton, T. (2014). Game design workshop. Boca Raton. Taylor \& Francis Group.

Csikszentmihalyi, M. (2014). The Systems Model of Creativity: The Collected Works of Mihaly Csikszentmihalyi. Dordrecht: Springer

Georgieva-Tsaneva, G.. (2018) Increasing the Quality of Education for Blind Students, through Improving Web Accessibility to Digitized Libraries, Software Systems and Databases. Proceedings of EDULEARN18 Conference. IATED Academy. Vol. 10. Pp. 4492-4497

Georgieva-Tsaneva, G. (2019) Innovative Methods in Medical Education in Bulgaria: Video Materials and Serious Games. International Journal of Emerging Technologies in Learning, Vol. 14 Iss. 16. Pp. 165-171.

Sabev, N., Georgieva-Tsaneva G., Bogdanova, G.. (2020) Research, analysis, and evaluation of web accessibility for a selected group of public websites in Bulgaria. Journal of Accessibility and Design for All. Vol. 10. Iss. 1. Pp. 124-160.

SVETOSLAV KOSEV

kosevsa@ts.uni-vt.bg

"Cyril and St. Methodius" University of Veliko Tarnovo Veliko Tarnovo, Bulgaria 

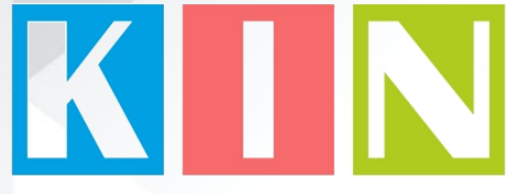

\section{ISSN: 2367-8038}

\section{Съставители \\ Петко Ст. Петков \\ Галина БогАанова}

Материалите в сборника са обект на авторско право. Разрешава се безвъзмезАното ползване на техни електронни/ хартиени копия само за мична употреба или обучение, при пьлно цитиране на текущата страница и слеА писмена Аек^арация от цитиращия за ^ипса на търговски намерения.

Научната поредица е регистрирана в НАЦИА С № 1209

() Авторски колектив, 2021

Техническо реАактори: Калина Сотирова-Вълкова Николай Ноев Паска^ Пиперков

\section{Editors}

Petko St. Petkov

Galina Bogdanova

This work is subject to copyright.

Open and free of charge use of digital/hard copies of publications is granted only for personal or educational use, with full citation of the current page, and after written declaration of the quoting side for notcommercial Intention.

Science series has been registered in NACID with No. 1209

() Authors` Group, 2021

Technical editors:

Kalina Sotirova-Valkova

Nikolay Noev

Paskal Piperkov

\section{ISSN: 2367-8038}

том 7, брой $1(10) / 2021$

vol. 7 , issue $1(10) / 2021$ 